\title{
Latency of the Achilles tendon reflex for detection of reduced functions of the peripheral nervous system in workers exposed to lead
}

\author{
Yasutaka Ogawa, Mamoru Hirata, Akira Okayama, Yoko Endo Ichikawa, Shigeru Goto
}

\begin{abstract}
The latency of the soleus muscle potential, evoked by a tap of the Achilles tendon, was used in the mass assessment of healthy male workers exposed to lead. Three groups were studied: a control, a low exposure, and a high exposure group. Mean blood lead concentrations were $9 \cdot 3,19 \cdot 2$, and $53.1 \mu \mathrm{g} / 100 \mathrm{ml}$ respectively. Latencies were adjusted for age and height and then compared among the three groups. The mean corrected latency of the high exposure group showed a $4 \%$ increase compared with the other two groups $(p<0.01)$. The latencies of the other two groups showed no between group differences. These results were consistent with previous neurophysiological studies done by many researchers on workers exposed to lead. They suggested that nerve conduction velocities decreased from 3 to $13 \%$ among workers whose mean blood lead concentrations were more than $30 \mu \mathrm{g} / 100 \mathrm{ml}$. The method was simple, time conserving, noninvasive, and non-aversive, and provided a quantitative measure of the nerve conduction velocities of peripheral nerves. Thus it may be useful for early detection of occupationally related impairment of peripheral nerves.
\end{abstract}

(British Journal of Industrial Medicine 1993;50:229-233)

Department of Public Health and Environmental Medicine, The Jikei University School of Medicine, Tokyo, Japan

Y Ogawa

Department of Occupational Health, Osaka Prefectural Institute of Public Health, Osaka, Japan

M Hirata

Department of Health Science and Administration, Shiga University of Medical Science, Ohtsu, Japan

A Okayama

Department of Public Health, Kansai Medical

University, Moriguchi, Japan

Y E Ichikawa

Nara University of Education, Nara, Japan

S Goto
Due to the limited chance of exposure to neurotoxic substances, acute outbreaks of neurological diseases in occupational circumstances are rare but the incidences of subclinical neurotoxicity by industrial substances are not sufficiently known. Early detection of such subclinical neurotoxicity in workers is important to prevent the occurrence of occupational neurological diseases. Therefore, quantitative techniques for the assessment of neurotoxicity or neurological changes are needed. In most workplaces clinical disease does not seem to be present and so extensive study is not required. The assessment of subclinical neurotoxicity therefore, is better carried out during pre-employment testing and periodic health monitoring. Acceptable techniques on such occasions should be rapidly administered, inexpensive, and non-threatening. Measurements of nerve conduction velocity have been recommended to evaluate peripheral nerve toxicity. ${ }^{1}$ Although the measures are quantitative and non-invasive, they tend to inflict pain on the subjects, are time consuming, and require some technical training on the part of the examiner. For these reasons, nerve conduction testing methods may be deemed inappropriate for use in this field. ${ }^{2}$

The stretch reflex method, if quantitative, best fits the requirements for mass assessment. Although there have been many previous attempts at quantifying this tendon reflex ${ }^{34}$ interest has focused mainly on the quantification of the movement or the strength of the reflex movement. Thus only a few studies have involved the latency. ${ }^{56}$ One reason for this may be that in clinical situations researchers can easily use the electrically evoked potential techniques of measurement of nerve conduction velocity, $H$ wave, $F$ wave, and so on. Therefore, the use of the latency, which is more closely related to the nerve conduction time than the kymogram, may have been thought to be unnecessary. However, for regular mass assessment, when the measurement of nerve conduction velocity is difficult to carry out, the latency of the tendon reflex is the most appropriate variable for the quantification of nerve conduction time. In this study we employed this measurement technique while 


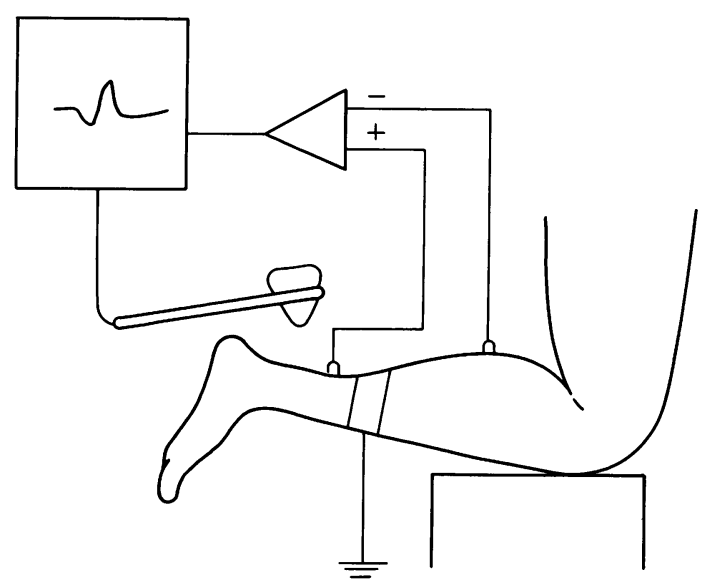

Figure 1 Diagram of experimental arrangement.

assessing the peripheral nerve dysfunction of workers exposed to lead to evaluate its usefulness.

\section{Materials and methods SUBJECTS}

One hundred and thirty three healthy male workers were chosen from five factories. Workers from two factories did not use lead as product materials and were classified as the non-exposed control group (C). Workers from another factory used lead powder $\left(\mathrm{PbO}_{2}\right)$ with protective tools and had regular education about how to decrease the exposure. Consequently, workers from this factory were classified as a low lead exposure group $(\mathrm{L})$. Workers from the other two factories, which were small scale industries, were repeatedly exposed to lead fumes or lead stearate powder. Both workplaces provided less than ideal working conditions for workers exposed to lead because of limited space and insufficient installations for suppressing the leakage of noxious materials. Therefore the workers from these two factories were classified as a high lead exposure group $(\mathrm{H})$. According to the record of these factories, none of the workers were exposed to other chemicals or metals known to have peripheral neurotoxicity in the workplace.

On examination of health records, workers with diabetes mellitus or blood glucose concentrations above $140 \mathrm{mg} / 100 \mathrm{ml}$, along with alcohol drinkers whose consumption amounted to more than $80 \mathrm{~g} /$ day were excluded. Physical health examinations showed no workers with peripheral nerve disorder, nor any with radicular lesions.

\section{METHODS}

Our study was performed in accordance with the Japanese industrial safety and health law-that is, each factory under study was required to provide periodic health examinations for workers exposed to lead in the workplace. ${ }^{7}$ Examination room temperatures were controlled so as not to be under $20^{\circ} \mathrm{C}$ during the measurements. The tendon reflex of the right soleus muscle (the Achilles tendon reflex) was examined (fig 1). The subjects were in the standing position with the right knee flexed at a 90 degree angle and resting on a stool with the subject's ankle hanging freely over the end of it. The tendon percussions were made by a hand held hammer (Medelec patellar hammer) that produced a short circuit mechanically when the hammer was tapped; the signal worked as a trigger pulse. Reflex potentials of soleus muscle were recorded from surface electrodes (stainless steel: size $0.8 \mathrm{~cm}^{2}$ ) placed on the skin with electrolyte gel and surgical tape. An active recording electrode was placed on the mid-dorsal line $3 \mathrm{~cm}$ above the lower margin of the gastrocnemius muscle of the calf (modified from Hugon $^{8}$ ). A reference recording electrode was placed $2 \mathrm{~cm}$ above the fibular head of the Achilles tendon for monopolar montage. ${ }^{9}$ A ground electrode was placed at the ankle. The evoked muscle potentials were amplified, bandpass filtered $(2 \mathrm{~Hz}$ and $10 \mathrm{kHz}$ ), and displayed with a portable EMG recorder (Medelec MS7). They were then photographed with a Polaroid camera.

Measurements were taken after the subjects had adapted to the room temperature for 10 minutes. Each subject was instructed to relax and a minimum of five stimuli were applied with sufficient strength to evoke maximal responses. The intervals between tendon taps were at least five seconds in duration. Amplitudes were measured from the peak negative to the peak positive deflection and the wave of maximum amplitude was selected for data analysis. Latencies of the waves (Lts) were measured from the stimulus artifact to the first deflection of the potential from the baseline. The skin temperature at the belly of the calf was monitored by an infrared detector (Optex HR1PS, Japan). The height of each worker was measured.

Venous blood samples were regularly taken from the workers for blood chemistry during the periodic health examinations. They were collected into heparinised lead free glass tubes and the concentrations of whole blood lead $(\mathrm{Pb}-\mathrm{B})$ were determined using electrothermal atomic absorption spectrophotometry. ${ }^{10}$

\section{ANALYTICAL METHODS}

Firstly the Lts of three groups were compared by analysis of covariance (ANCOVA) using height, skin temperature, and age as covariates. Then stepwise multiple regression analyses were performed with height, skin temperature, and age as independent variables (in, $\alpha=0 \cdot 15$; out, $\alpha=0 \cdot 15$ ). Each $\mathrm{Lt}$ was corrected to $\mathrm{Lt}_{c}$, which was a value of $\mathrm{Lt}$ at the mean 
Table 1 Age distribution for control (C), low exposure (L), and high exposure $(H)$ groups

\begin{tabular}{|c|c|c|c|c|c|}
\hline & \multicolumn{5}{|c|}{ Age (y) } \\
\hline & $<25$ & $25-34$ & $35-44$ & $\geqslant 45$ & Total \\
\hline $\begin{array}{l}\text { Lead group: } \\
\text { C } \\
\text { L } \\
\text { H }\end{array}$ & $\begin{array}{r}9 \\
11 \\
1\end{array}$ & $\begin{array}{r}11 \\
13 \\
2\end{array}$ & $\begin{array}{r}21 \\
14 \\
6\end{array}$ & $\begin{array}{r}27 \\
5 \\
4\end{array}$ & $\begin{array}{l}68 \\
43 \\
13\end{array}$ \\
\hline Total & 21 & 26 & 41 & 36 & 124 \\
\hline
\end{tabular}

value of each independent variable. It was assumed that the resulting regression line would explain the variation depending on the variables. $L t$ was further corrected to $\mathrm{Lt}_{167}$, which was calculated on the assumption that the latency was in proportion to the height of the subject.

To compare the mean values of three groups, analysis of variance (ANOVA) was first applied and then the method of Scheffe was used to compare the differences between groups. Multiple comparison of Pearson's correlation coefficients were tested by Bonferroni adjusted probabilities.

\section{Results}

Three workers from group $\mathrm{C}$ and four from group $\mathrm{L}$ were unsuccessful in evoking the tendon reflex. The workers whose calf skin temperatures were under $30^{\circ} \mathrm{C}$ were excluded from the study (one in group L, one in group $\mathrm{H}$ ). The remaining 124 subjects were used for our analysis. Table 1 shows the age distribution of the analysed workers in the three groups.

Table 2 shows the group means and standard deviations (SDs) of age, height, skin temperature, and $\mathrm{Pb}-\mathrm{B}$. The mean age of group $\mathrm{L}$ was low compared with that of group $C(p<0.05)$. The mean skin temperature of group $\mathrm{H}$ was low compared with that of $\mathrm{C}$ and $\mathrm{L}(\mathrm{p}<0.01)$. The mean $\mathrm{Pb}-\mathrm{Bs}$ of three groups were statistically different between groups $(p<0.01)$. The concentrations were highest in group $\mathrm{H}$ and lowest in group $\mathrm{C}$.

Table 3 shows the correlation coefficients between the variates. Height was positively correlated with latency and negatively correlated with age. There

Table 2 Age, height, skin temperature (S temp), and blood lead concentrations ( $P$ b-B) for control $(C)$, low exposure $(L)$, and high exposure $(H)$ groups

\begin{tabular}{|c|c|c|c|}
\hline & $\begin{array}{l}C(n=68) \\
\text { Mean }(S D)\end{array}$ & $\begin{array}{l}L(n=43) \\
\text { Mean }(S D)\end{array}$ & $\begin{array}{l}H(n=13) \\
\text { Mean }(S D)\end{array}$ \\
\hline $\begin{array}{l}\text { Age }(y) \dagger \\
\text { Height }(\mathrm{cm}) \\
\text { S temp }\left({ }^{\circ} \mathrm{C}\right)_{+}^{+} \\
\mathrm{Pb}-\mathrm{B}(\mu \mathrm{g} / 100 \mathrm{ml}) \S\end{array}$ & $\begin{array}{r}39 \cdot 6(9 \cdot 7) \\
166 \cdot 1(6 \cdot 3) \\
33 \cdot 3(0 \cdot 8) \\
8 \cdot 5(2 \cdot 7)\end{array}$ & $\begin{array}{c}33.5(10.1) \\
168.3(5.6) \\
33.0(1.1) \\
19.2(10.7)\end{array}$ & $\begin{array}{c}40 \cdot 6(11 \cdot 1) \\
166 \cdot 6(5 \cdot 5) \\
31 \cdot 9(0 \cdot 8) \\
53 \cdot 3(15 \cdot 1)\end{array}$ \\
\hline
\end{tabular}

tp $<0.05$ between $\mathrm{C}$ and $\mathrm{L} ; \mathrm{tp}<0.01$ between $\mathrm{C}$ and $\mathrm{H}$ and between $\mathrm{L}$ and $\mathrm{H} ;$; $<<0.01$; between $\mathrm{C}, \mathrm{L}$, and $\mathrm{H}$.
Table 3 Correlation coefficients between age, height, skin temperature ( $S$ temp), and the latency of a mechanically elicited electromyogram of soleus muscle $(L t)$

\begin{tabular}{llll}
\hline & Age & Height & S temp \\
\hline Height & $-0.465^{\star \star}$ & & \\
S temp & 0.091 & -0.140 & \\
Lt & 0.062 & $0.436^{\star \star}$ & -0.116 \\
\hline${ }^{\star} \mathrm{p}<0.05 ;{ }^{\star \star} \mathrm{p}<0.01$. & &
\end{tabular}

was no correlation between $\mathrm{Lt}$ and skin temperature in the range $30 \cdot 1-35 \cdot 1^{\circ} \mathrm{C}$.

According to ANCOVA, the Lts of three groups were not evenly distributed. By stepwise multiple regression analysis age and height were selected as independent variables and skin temperature was discarded. Hence the corrected model for $\mathrm{Lt}$ became: $\mathrm{Lt}_{\mathrm{c}}=\mathrm{Lt}+\{0.057(37.6-$ Age $)+0 \cdot 188(166.9-$ Height) $\}$

where 37.6 and 166.9 are the means of age in years and height in $\mathrm{cm}$ of all the subjects. The second corrected model for $\mathrm{Lt}$ was:

$$
\mathrm{Lt}_{167}=(167 / \text { Height }(\mathrm{cm})) \times \mathrm{Lt}
$$

where 167 is the mean height of all the subjects in $\mathrm{cm}$.

Table 4 shows the means (SDs) of $L t, \mathrm{Lt}_{\mathrm{c}}$ and $\mathrm{Lt}_{167}$ for the three groups. Each latency was significantly different between group $\mathrm{H}$ and group $\mathrm{C}$, and between group $\mathrm{H}$ and group $\mathrm{L}$. Each adjustment of confounding variables decreased the SD of each group. The correlation coefficient between $\mathrm{Lt}_{c}$ and $\mathrm{Lt}_{167}$ was 0.94 (fig 2).

\section{Discussion}

Latency of the muscle action potential, $\mathrm{Lt}$, elicited by the tendon tap, is composed of several components: (1) the speed of stretching a tendon by the tendon tap (the spread time of the tension wave to the muscle spindle) and the muscle spindle activation time; (2) the conduction time of the Ia sensory fibre from muscle spindle to the spinal cord; (3) the synaptic delay at the spinal cord; (4) the conduction time of the $\alpha$ motor fibre from the anterior horn to the neuromuscular junction; (5) the synaptic delay at the neuromuscular junction.

Table 4 Latency $L t$ and corrected latencies $L_{t c}$ and $L t_{167}$ for control $(C)$, low exposure $(L)$, and high exposure $(H)$ groups

\begin{tabular}{llll}
\hline & $\begin{array}{l}C(n=68) \\
\text { Mean }(S D)\end{array}$ & $\begin{array}{l}L(n=43) \\
\text { Mean }(S D)\end{array}$ & $\begin{array}{l}H(n=13) \\
\text { Mean }(S D)\end{array}$ \\
\hline $\mathrm{Lt}(\mathrm{ms}) \dagger$ & $27 \cdot 0(1.9)$ & $26 \cdot 9(1 \cdot 5)$ & $28 \cdot 3(2 \cdot 2)$ \\
$\mathrm{L}_{\mathrm{tc}}(\mathrm{ms}) \ddagger$ & $27 \cdot 1(1 \cdot 4)$ & $26.9(1.4)$ & $28 \cdot 2(2 \cdot 1)$ \\
$\mathrm{Lt}_{167}(\mathrm{~ms}) \ddagger$ & $27 \cdot 2(1.5)$ & $26 \cdot 7(1 \cdot 4)$ & $28 \cdot 4(2 \cdot 1)$ \\
\hline
\end{tabular}

†p $<0.05$ between $\mathrm{C}$ and $\mathrm{H}$ and between $\mathrm{L}$ and $\mathrm{H} ;$ †p $<0.05$ between $C$ and $H$ and $p<0.01$ between $L$ and $H$. 


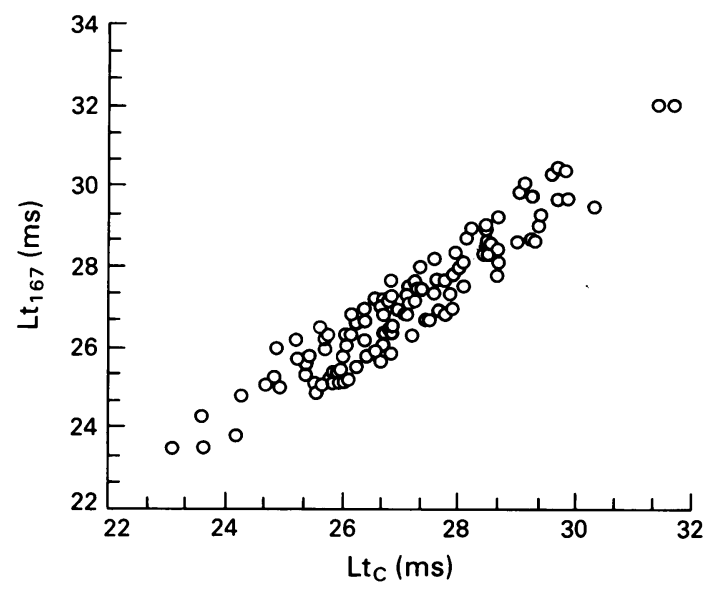

Figure 2 Relation between two corrected latencies $L t_{c}$ and $L t_{167}$.

The spread of a tension wave after the tendon tap and the activation of the muscle spindle takes roughly $2 \mathrm{~ms}+$ synaptic delay of the neuromuscular junction in ms. ${ }^{11}$ The variation of this component is due to the tapping technique and the length of the muscle. By our measurements intraindividual variations were not more than $3 \%$ in coefficient of variation, which is about $0.8 \mathrm{~ms}$. The spinal synaptic delay of the $\mathrm{H}$ reflex arc is less than $1 \mathrm{~ms}^{12}{ }^{13}$; thus the contribution of summed (3) and (5) to Lt may be less than $2 \mathrm{~ms}$. The remaining part of $L t(\approx 23 \mathrm{~ms}$ ), which is about $85 \%$ of $\mathrm{Lt}$, is composed of the nerve conduction time of the afferent Ia fibre and the efferent $\alpha$ fibre.

In animal studies there is evidence that low concentrations of lead depress or block synaptic transmission but do not noticeably affect transmission time. ${ }^{1415}$ There is also evidence that synaptic delay is dependent on temperature, but it seems that it cannot change more than $0.05 \mathrm{~ms} /{ }^{\circ} \mathrm{C}$ around $30^{\circ} \mathrm{C}^{16}$ Therefore, there is little possibility for the change in synaptic transmission time to contribute to the increase that appeared in the Lt of group $\mathrm{H}$. This increase is probably due to the slowing of nerve conduction velocities.

According to the assumptions we have made above, if the latency elongation is $4 \%$, as found in this study, the mean nerve conduction velocities of nerves relating to the reflex will decrease by $4.5 \%$. This estimation is consistent with the nerve conduction velocity studies of many researchers. Triebig $e t$ al showed a $1 \cdot 5-4 \cdot 2 \%$ decrease among ulnar nerve conduction velocities in workers whose mean $\mathrm{Pb}-\mathrm{B}$ was $80 \mu \mathrm{g} / 100 \mathrm{ml} .{ }^{17}$ Muijser et al reported a $2-7 \%$ decrease among ulnar and median nerve conduction velocities in workers whose mean $\mathrm{Pb}-\mathrm{B}$ was $53.2 \mu \mathrm{g} /$ $100 \mathrm{ml},{ }^{18}$ and $\mathrm{He}$ et al showed a $3 \cdot 6-13 \cdot 7 \%$ decrease among ulnar, median, peroneal, and sural nerve conduction velocities in workers whose mean $\mathrm{Pb}-\mathrm{B}$ (geometric) was $40 \cdot 0 \mu \mathrm{g} / 100 \mathrm{ml} .^{19}$

Although this study's mean (Pb-B of $20 \mu \mathrm{g} /$ $100 \mathrm{ml}$ ) showed no change in Lt compared with $9 \mu \mathrm{g} /$ $100 \mathrm{ml}$, a mean of $50 \mu \mathrm{g} / 100 \mathrm{ml}$ did. This change is also consistent with former studies. Seppäläinen $e t$ al identified the $\mathrm{Pb}-\mathrm{B}$ concentration threshold that changes nerve conduction velocity to be $40-50 \mu \mathrm{g} /$ $100 \mathrm{ml} .{ }^{20}$ Schwartz et al found the threshold concentration of children to be $30 \mu \mathrm{g} / 100 \mathrm{ml} .^{21}$

The mean skin temperature of group $\mathrm{H}$ was significantly lower than the temperatures of the other two groups indicating that this might have influenced $\mathrm{Lt}^{22}$ Despite this fact, this difference does not account for the between group differences in Lt because there was no positive correlation between skin temperature and $\mathrm{Lt}$ (in the study's temperature range). Skin temperature on the calf may not be indicative of deep skin temperatures where the nerve trunk runs. It may in fact be disturbed by the thickness of underlying fat tissue. ${ }^{23}$ Accordingly, further studies are needed in this area.

Nerve conduction time is related to the nerve conduction velocity and the length of the conduction pathway. This may explain the result that there was a high correlation between $\mathrm{Lt}$ and height. Guiheneuc and Bathien also showed a linear relation $(r=0.95)$ between the height of the subject and the interval between $M$ wave and $\mathrm{H}$ wave, which did not include (1) and (5) ${ }^{24}$ According to this relation, $L t$ needs to be corrected for height in epidemiological studies. Our analysis showed that the correction of $\mathrm{Lt}$ with height, assuming that $\mathrm{Lt}$ is in proportion to height, was simple and effective.

The method we introduced was non-invasive, non-aversive, and easy to perform within a short time. For these reasons, it may be deemed acceptable for the periodic mass monitoring of workers exposed to neurotoxic substances. As previously discussed, this method is not specific for measurement of nerve conduction velocities. Even if some change in latency was found between groups, therefore, we cannot pinpoint the exact portion responsible. This problem requires further examination. If the effects of a material are well known, however, such as for inorganic lead, which mainly affects the fibres of the peripheral nervous system, then our method may be useful for screening the effects on this system. Furthermore, this method included measurements of conductivities of the proximal as well as the distal portion of the peripheral nervous system. For a neurotoxicant such as $\beta, \beta$-iminodipropionitrile that produces neuropathy in the proximal portion earlier than the distal portion of the peripheral nervous system, ${ }^{25}$ this method may be useful in assessing the dysfunction of the proximal portion.

We thank Miss Midori Kobayashi for her linguistic help. 
Requests for reprints to: Yasutaka Ogawa, Department of Public Health and Environmental Medicine, The Jikei University School of Medicine, 3-25-8 Nishishimbashi, Minato-ku, Tokyo 105, Japan.

1 World Health Organisation. Neurophysiological methods in neurotoxicology. In: Principles and methods for the assessment of neurotoxicity associated with exposure to chemicals. Geneva: WHO, 1986:59-70. (Environmental health criteria 60.)

2 Moody L, Arezzo J, Otto D. Screening occupational populations for asymptomatic or early peripheral neuropathy. J Occup Med 1986;28:975-86.

3 Lambert EH, Underdahl LO, Beckett S, Mederos LO. A study of the ankle jerk in myxedema. J Clin Endocrinol 1951;11: 1186-205.

4 Dietrichson P, Sorbye R. Clinical method for electrical and mechanical recordings of the mechanically and electrically elicited ankle reflex. Acta Neurol Scand 1971;47:1-21.

5 Gilliatt RW, Willison RG. Peripheral nerve conduction in diabetic neuropathy. J Neurol Neurosurg Psychiatry 1962;25: 11-8.

6 Watanabe T. T-wave of Achilles tendon reflex in relation to aging and sex difference. Japanese Journal of Electroencephalography and Electromyography 1980;9:138-45. (In Japanese.)

7 Ministry of Labour Japan. Labour laws of Japan 1990. Tokyo: Institute of Labour Administration, 1991:145-6.

8 Hugon $M$. Methodology of the Hoffmann reflex in man. In: Desmedt JE, ed. New developments in electromyography and clinical neurophysiology. Vol 3. Basel: Karger, 1973:277-93.

9 Little JW, Hayward LF, Halar E. Monopolar recording of $\mathrm{H}$ reflexes at various sites. Electromyogr Clin Neurophysiol 1989;29:213-9.

10 Kosaka $\mathrm{H}$, Miyajima $\mathrm{K}$. Studies on the determination of the lead level in whole blood by flameless atomic absorption spectrophotometry. Proceedings of the Osaka Prefectural Institute of Public Health 1983;21:17-20. (In Japanese.)

11 Gassel MM, Ott KH. An electrophysiological study of the organization of innervation of the tendon jerk in humans. In: Desmedt JE, ed. New developments in electromyography and clinical Neurophysiology. Vol 3. Basel: Karger, 1973:277-93.

12 Renshaw B. Activity in the simplest spinal reflex pathways. $J$ Neurophysiol 1940;3:373-87.
13 Magladery JW, Porter WE, Park AM, Teasdall RD. Bulletin of the Johns Hopkins Hospital 1951;88:499-519.

14 Manalis RS, Cooper GP. Presynaptic and postsynaptic effects of lead at the frog neuromuscular junction. Nature 1973;243: 354-6.

15 Kober TE, Cooper GP. Lead competitively inhibits calciumdependent synaptic transmission in the bullfrog sympathetic ganglion. Nature 1976;262:704-5.

16 Hille B. Neuromuscular transmission. In: Ruch T, Patton HD, eds. Physiology and biophysics. Vol IV. Excitable tissues and reflex control of muscle. 20th ed. Philadelphia: WB Saunders Co, 1982:150-69.

17 Triebig G, Weltle D, Valentin H. Investigations on neurotoxicity of chemical substances at workplace. V. Determination of the motor and sensory nerve conduction velocity in persons occupationally exposed to lead. Int Arch Occup Environ Health 1984;53:189-204.

18 Muijser H, Hoogendijk EMG, Hooisma J, Twisk DMA. Lead exposure during demolition of a steel structure coated with lead-based paints. II Reversible changes in the conduction velocity of the motor nerves in transiently exposed workers. Scand J Work Environ Health 1987;13:56-61.

$19 \mathrm{He} \mathrm{F}$, Zhang SO, Li G, Zhang Sh, Huang Y, Wu Y. An electroneurographic assessment of subclinical lead neurotoxicity. Int Arch Occup Environ Health 1988;61:141-6.

20 Seppäläinen AM, Hernberg S, Kock B. Relationship between blood lead levels and nerve conduction velocities. Neurotoxicology 1979;1:313-32.

21 Schwartz J, Landrigan PJ, Feldman RG, Silbergeld EK, Baker $\mathrm{Jr}$ EL, Lindern $\mathrm{H}$ von. Threshold effect in lead-induced peripheral neuropathy. J Pediatr 1988;112:12-7.

22 de Jesus PV, Hausmanowa-Petrusewicz I, Barchi RL. The effect of cold on nerve conduction of human slow and fast nerve fibers. Neurology 1973;23:1182-9.

23 Bell KR, Lehmann JF. Effect of cooling on $\mathrm{H}$ - and T-reflexes in normal subjects. Arch Phys Med Rehabil 1987;68:490-3.

24 Guiheneuc P, Bathien N. Two patterns of results in polyneuropathies investigated with the H reflex. J Neurol Sci 1973; 30:83-94.

25 Lowndes HE, Delio DA, Gold BG. Electrophysiological investigation of IDPN neuropathy - initial studies. Neurotoxicology 1985;6:25-42.

Accepted 8 June 1992 